\title{
BAYLE E OS IMPASSES DA RAZÃO
}

\author{
Plínio Junqueira Smith* \\ psmith@usjt.br
}

RESUMO $O$ objetivo do artigo é compreender como Bayle, no seu Dicionário, avalia a força da razão. Primeiro, apresento como seria o bom funcionamento da razão e de que modo esta, apoiando-se tanto nas ideias claras e distintas, como em princípios lógicos, metafísicos e morais, poderia estabelecer algumas verdades em filosofia. Em seguida, passo em revista quais seriam as principais dificuldades levantadas por Bayle para que a razão possa alcançar verdades e que alcance teria, segundo o filósofo, cada uma delas. Na parte final, faço um balanço das análises precedentes e proponho que, para Bayle, a razão não é destruida por essas dificuldades, mas, ainda assim, seria incapaz de estabelecer qualquer verdade em filosofia.

Palavras-chave razão, experiência, noções comuns, retorsão, paradoxos lógicos, antinomia.

RÉSUMÉ L'objectif de l'article est de comprendre comme Bayle, dans le Dictionnaire, évalue la force de la raison. Premièrement, on présente le bon fonctionnement de la raison et de quelle manière on pourrait établir quelques vérités en philosophie, en nous appuyant sur les idées claires et distinctes et sur les principes logiques, métaphysiques et moraux. Ensuite, on examine chaque difficultée de la raison pour determiner ces vérités. Dans la partie finale, on fait un bilan critique des analyses précendantes et on propose que, selon Bayle, la raison n'est pas détruite par ces difficultées, et, cependant, elle n'est pas capable d'établir n'importe quelle vérité en philosophie.

* UNIFESP, USJT, CNPq. Recebido em 21/07/2009. Aceito em 17/09/2009.

KRITERION, Belo Horizonte, no 120, Dez./2009, p. 377-390. 
Mots clés raison, expérience, notions communes, rétorsion, paradoxes logiques, antinomie.

\section{A força da razão}

Algumas passagens de Bayle sugerem fortemente que a verdade está ao alcance da razão. Ele teria aceitado não somente o critério cartesiano de verdade (as ideias claras e distintas), mas também a verdade de princípios lógicos, metafísicos e morais. A razão, quando opera regularmente, apóia-se nas ideias claras e distintas e faz inferências de acordo com os seus diversos princípios. Para Bayle, o raciocínio deve se orientar pelas ideias claras e distintas comuns a todos os homens. "É tão impossível filosofar bem sem a evidência das ideias como navegar bem sem ver a estrela polar ou sem uma bússola." ("Aristóteles", M) As ideias claras e distintas constituem, assim, uma referência fundamental para balizar a busca da verdade e para rejeitar todas aquelas doutrinas que não estão conforme a essas ideias.

Uma teoria filosófica que contradiz nossas ideias claras e distintas deve ser rejeitada. Esse é, por exemplo, o caso das principais críticas a Espinosa. A filosofia de Espinosa seria "a mais monstruosa hipótese que poderia ser imaginada, a mais absurda e a mais diametralmente oposta às noções mais evidentes de nossa mente (N)." ("Espinosa", texto) Bayle deleita-se em mostrar como Espinosa vai sucessivamente opondo-se a uma gama de ideias claras e distintas. Por exemplo, ele trataria a ideia de extensão como se fosse una, e não divisível; não teria entendido a ideia de identidade, ao supor que duas árvores seriam somente duas modificações de uma substância; não teria empregado adequadamente a ideia de divisão; não teria compreendido a ideia muito clara de imutabilidade, pois a substância única, de acordo com essa ideia, seria mutável, mas ele teria dito que é imutável; finalmente, se confrontaria com a ideia de Deus, já que o atributo mais inseparável de Deus é a felicidade e o Deus espinosano seria infeliz ("Espinosa" N, I-III). ${ }^{1}$

Com relação aos princípios, é comum Bayle empregar uma linguagem como a que está presente na discussão sobre a doutrina da harmonia préestabelecida de Leibniz: "Se consultar as noções comuns, você descobrirá que..." ("Rorarius", L) ou empregar expressões como "para bem raciocinar" ("Dicearque" C). Em geral, quando fala de raciocinar bem, Bayle entende que 
a conclusão é aceitável para todos, inclusive para ele. Ele emprega ainda outra expressão, "para raciocinar de maneira consequente" ("Dicearque", C, L), em que a conclusão deve ser aceita por quem supõe um dado princípio filosófico. Nem todos os filósofos extraem, de seus princípios, as consequências que deles se seguem. Bayle procura, então, retificar seus sistemas, mantendolhes a coerência. Assim, o raciocínio lógico e a extração de consequências inevitáveis dos princípios aceitos fazem parte da boa filosofia.

Uma filosofia que se choca com princípios básicos é condenável. Bayle observa, no caso de Espinosa, que "as consequências que tirei e os princípios que usei para combater essas consequências estão inteiramente de acordo com as regras do raciocínio" ("Espinosa”, texto), mas Espinosa não as teria respeitado. "Um homem como Espinosa ficaria absolutamente calado se raciocinasse logicamente." ("Espinosa" N) Vê-se, portanto, que na discussão filosófica é preciso seguir estritamente as regras da razão. Ora, Espinosa quebra justamente a principal de todas as regras, a saber, o princípio de nãocontradição, pois sustentaria que "dois termos contraditórios são, então, verdadeiros dele [de Deus], o que é a destruição dos primeiros princípios da metafísica." ("Espinosa", N)

Talvez se possa dizer que há uma gradação de clareza entre as ideias, assim como haveria uma gradação entre os princípios. Bayle indica, com freqüência, quando uma ideia é mais clara ou quando, embora clara, não é tão clara quanto outras ideias. Por exemplo, ele diz que "as ideias mais seguras e mais claras de ordem nos ensinam que um ser que existe por si mesmo, que é necessário, que é eterno, deve ser único, infinito, todo poderoso e dotado de todos os tipos de perfeição." ("Maniqueistas" D; itálico meu). ${ }^{2}$ A ideia mais clara de todas seria a de extensão.

Já os princípios admitiriam graus de evidência. "É preciso saber que nem todas as proposições, que se chamam princípios, são igualmente evidentes." ("Maldonat" L) Dois princípios ou axiomas fundamentais, ao menos, têm um grau máximo de evidência. Se duas coisas são iguais a uma terceira, então são iguais entre si. Esse princípio é o fundamento de todos os silogismos, sendo indispensável para a filosofia. Segundo, é uma máxima da razão que nada pode ser produzido a partir do nada (ex nihilo nihil fit). O princípio de causalidade é outra noção comum que constitui nossa forma de pensar, sem o qual não seríamos capazes de raciocinar e inferir uma coisa a partir de outra.

2 Pode-se falar também numa ordenação hierárquica entre as ideias (cf. "Maniqueístas" D). 
Para a razão, é inconcebível como algo poderia ser criado a partir do nada. Bayle supõe que pode haver oposição entre duas máximas ou princípios.

\section{Os obstáculos da razão}

No entanto, não é fácil a razão estabelecer a verdade de uma hipótese. Passarei em revista alguns tipos de argumentos que poderiam aniquilar a razão ou impor-lhe severos limites.

Um tipo de argumento frequentemente empregado por Bayle é o argumento ad hominem, que obriga o adversário a raciocinar de acordo com os princípios de sua filosofia. Seja ao apontar uma contradição, seja ao extrair consequências inaceitáveis ou absurdas de seus princípios, Bayle refutaria doutrinas filosóficas, como a doutrina aristotélica do primeiro motor ("Zabarella", G). Até que ponto esses argumentos levam Bayle a suspeitar da capacidade da razão?

A argumentação ad hominem é muito persuasiva, pois, ao raciocinar somente supondo o que o adversário aceita, obriga-o a aceitar a conclusão, se os argumentos forem válidos. "Não seria fácil aos peripatéticos refutar essas razões de Zabarella, pois este argumenta contra eles ad hominem, ele se vale de sua doutrina das formas substanciais e da virtude motora e primitiva da alma dos animais." ("Zabarella", G) A força dessa argumentação, longe de rejeitar a razão, consiste na exigência de coerência. Além disso, seus limites são evidentes, já que somente os princípios do adversário são questionados. Para nossos propósitos, essa limitação é crucial, pois uma argumentação ad hominem mostra somente que certos princípios filosóficos devem ser rejeitados, mas não as ideias claras, nem os princípios evidentes. Dado que as ideias claras e os princípios são aceitos e empregados por todos os homens, uma argumentação ad hominem não poderá jamais questioná-los, pois focalizará somente o que é específico dessa ou daquela doutrina. "Os modernos, que rejeitaram com razão esses dogmas [dos peripatéticos] refutariam [Zabarella] sem esforço e não veriam nada espinhoso em suas objeções." ("Zabarella”, G) Assim, a argumentação ad hominem é antes uma defesa da razão, ao denunciar a incoerência de uma filosofia, e limitada para atacar ideias claras e princípios evidentes.

Outro tipo de argumento frequentemente usado por Bayle é a retorsão, que faz voltar contra um filósofo os mesmos argumentos que este dirigiu contra a doutrina adversária. Qual o alcance ou o poder destrutivo da retorsão?

Solère (2004, p. 136) definiu a retorsão assim: "quando o ataque sucumbe à mesma dificuldade que a tese que combate, o defensor tem o direito de não 
modificar sua própria posição, visto que a do adversário não é melhor.” A retorsão seria uma estratégia defensiva, segundo a qual só se deve abandonar uma posição, caso a posição do atacante seja mais satisfatória. Dessa perspectiva, a retorsão, longe de limitar o uso da razão, permitiria confirmar a solidez de uma posição filosófica.

Talvez se possa ver, na retorsão, um ataque simultâneo às duas posições. Embora aquele que usa a retorsão possa defender-se de um ataque, o fato é que ambas as posições sucumbem aos mesmos argumentos. A retorsão não permite estabelecer a superioridade de uma posição. Se fosse primeiramente atacado, o atacante poderia igualmente recorrer à retorsão, garantindo igualmente a inexpugnabilidade de sua posição. Assim, quando já se tomou um partido, a retorsão é uma forma de argumentação defensiva eficaz. Mas, se ainda não se tomou nenhum partido, a retorsão é um instrumento que incide igualmente sobre os dois lados da questão, pois estão sujeitos ao mesmo tipo de objeção. ${ }^{3}$ Para julgar sem preconceito ou posição prévia, seria preciso despir-se das crenças e, de maneira imparcial, examinar os argumentos dos dois lados. Nesse caso, não somente a retorsão deixaria de ser uma arma defensiva, mas seria preciso "estar revestido de um espírito cético e pirrônico" ("Pellison" E) para poder ser somente juiz, e não parte interessada. Essa posição neutra, embora seja detestada por ambos os contendores, é aquela que a razão exige de nós ("Crisipo" G).

Pode alguém, então, almejar a destruição da razão recorrendo à retorsão? Não, pois a retorsão é uma exigência de consistência. Toda filosofia deve submeter-se a um teste rigoroso: resistir às objeções por ela endereçadas a outras filosofias. Se os argumentos ad hominem correspondem à coerência que uma doutrina deve guardar com seus princípios, a retorsão indica a coerência com as críticas formuladas. Esse é, certamente, um teste indispensável para a adesão racional a uma doutrina. Muitas, infelizmente, não passam nesse teste. Longe de se ver condenada pelo mecanismo da retorsão, a razão condena consistentemente os dois contendores pelos mesmos argumentos.

Outra dificuldade apontada por Bayle diz respeito às ideias claras. Se as ideias claras fossem um critério confiável de verdade, não poderiam falhar em nenhum caso. Ora, a experiência parece contradizer muitas vezes o que somos levados a esperar por raciocínios baseados somente nessas ideias. Raciocínios a posteriori, apoiados na experiência, mostrariam a falsidade do 
que concluímos com raciocínios a priori. Portanto, as ideias claras e distintas não são um critério de verdade.

Esse descompasso entre ideias claras e experiência (ou entre raciocínio a priori e a posteriori) se manifesta, por exemplo, na questão do vácuo. Os cartesianos sustentaram que nossa ideia clara de extensão exclui o vácuo. A negação do vácuo, entretanto, parece implicar a negação do movimento, já que no pleno o movimento seria ininteligível. Portanto, deve-se rejeitar o movimento como algo meramente ilusório. Essa seria a consequência de um raciocínio a priori apoiado exclusivamente na ideia clara de extensão. Os raciocínios a posteriori seguem o caminho inverso. Partindo da realidade do movimento, os matemáticos da natureza (Newton e Huygens) aceitaram a realidade do vácuo, mesmo que não tenhamos dele uma ideia clara ("Zenão" I). Bayle situa-se do lado do homem comum e admite o movimento aparente ("Zenão" G), que é diferente do movimento ilusório. Assim, diz Bayle, a ideia clara de extensão "nos enganou miseravelmente" ("Leucipo" G). Em suma, devemos reconhecer que a teoria que se apóia nas ideias não explica os fenômenos e nossa experiência.

Segundo Bayle, dois são os critérios pelos quais devemos julgar se uma teoria ou hipótese é aceitável: a clareza e distinção de suas ideias e a capacidade de explicar a experiência ("Maniqueistas" D). Esse teste empírico configurase numa dificuldade insuperável para os defensores de um único princípio do bem, que excluiria o mal do mundo, já que a experiência do mal é inegável. Bayle parece aceitar que a explicação da experiência é mais importante do que a clareza das ideias. Ao imaginar um diálogo entre Melisso e Zoroastro, diz (pela boca de Zoroastro):

Desafio você [Melisso] a encontrar nos seus princípios a razão desse fenômeno, como eu a encontro nos meus. Reconquisto, portanto, a vantagem: você me supera na beleza das ideias e nas razões a priori; e eu lhe supero na explicação desses fenômenos e nas razões a posteriori. E visto que a principal característica do bom sistema é ser capaz de dar a razão das experiências e que basta a incapacidade de explicá-las para provar que uma hipótese não é boa, embora pareça bela de outros pontos de vista, você deve estar de acordo que eu acerto o alvo ao admitir os dois princípios e que você, ao admitir apenas um, não o acerta. ("Maniqueistas" D)

Portanto, as ideias claras não somente não são o único critério de verdade, mas talvez sequer sejam o critério mais importante. A razão a priori acha-se desprovida de seu principal guia quando se confronta com a experiência e os raciocínios a posteriori.

Pode a experiência ir mais longe e contradizer princípios evidentes? Segundo Mori (2003, p. 398-9), Bayle sugere "que se poderia provar falso 
mesmo um axioma como 'o todo é maior que as partes' se a experiência nos fornecesse um contra-exemplo." Entretanto, a seu ver, essa possibilidade meramente sugerida por Bayle não deveria ser interpretada como uma admissão que estaríamos dispostos a negar um princípio dada uma suposta contradição com a experiência, já que esta não teria força para negá-lo. Bayle estaria somente ressaltando o papel da experiência no conhecimento empírico, uma vez que ele "simplesmente tinha a intenção de afirmar a impossibilidade de ir contra a experiência, que, em qualquer caso, sempre constitui o critério final de nossos juízos fatuais." Assim, a verdade dos princípios estaria a salvo dos contra-exemplos da experiência.

Permitiria o cristianismo questionar os princípios lógicos, metafísicos e morais? Esse ponto é explorado num diálogo entre dois abades, quando um deles mostra como os dogmas cristãos conduzem diretamente à destruição da razão e à impossibilidade de reconhecer a verdade ("Pirro" B). Bayle mostra, com detalhes, como esses dogmas minariam os princípios mais básicos da razão humana. "É uma queixa quase geral que a filosofia causa males à teologia, mas, de outro lado, é certo que a teologia é nociva à filosofia" (“Aristote”, X). Os dogmas cristãos implicariam a completa destruição da razão.

Essa oposição à razão, entretanto, sofre de um inconveniente grave, justamente por pressupor a aceitação arbitrária de alguns dogmas religiosos. Para a razão, não se podem aceitar dogmas controversos e não-provados; a aceitação arbitrária de certos dogmas torna vulnerável toda a argumentação que nesses se sustenta. A razão, longe de ser arruinada por esse ataque, resistir-lhe-á facilmente. Esse ataque à razão não a destrói, mas tão somente ressalta a incompatibilidade de duas perspectivas: ou se é religioso e, portanto, a razão é destruída; ou se é filósofo e, portanto, não haveria porque recusar os princípios, mantendo a razão todos os seus direitos. Para Bayle,

é preciso necessariamente optar entre a filosofia e o Evangelho: se você quiser acreditar somente no que é evidente e conforme às noções comuns, escolha a filosofia e abandone o cristianismo; se você quiser crer nos mistérios incompreensíveis da religião, escolha o cristianismo e abandone a filosofia, pois possuir a evidência e o incompreensível é o que não se pode (III Esclarecimento, IV).

Portanto, essa argumentação estabelece somente a incompatibilidade da razão com o cristianismo, jamais sua destruição.

Poder-se-ia pensar que, no entender de Bayle, paradoxos lógicos seriam capazes de lançar dúvidas sobre os primeiros princípios. Esses paradoxos poderiam questionar em particular a validade dos princípios lógicos, uma vez que estes, tendo algumas consequências desastrosas, se revelariam mais 
problemáticos do que pareceria à primeira vista. Certas proposições, como "esta afirmação é falsa", parecem violar o princípio de não-contradição. Segundo esse princípio, toda proposição é verdadeira ou falsa, mas a proposição em questão seria simultaneamente verdadeira e falsa: se é falsa, é verdadeira; e se é verdadeira, é falsa. Um princípio lógico, entretanto, não deveria admitir nenhuma exceção. Poderiam os paradoxos lógicos, então, colocar em questão os princípios mais básicos da razão?

Segundo Ryan, embora não seja possível dar uma solução lógica aos paradoxos, é possível proteger o princípio de não-contradição, preservando a razão. "Na ausência de uma solução aceitável do paradoxo, pode-se continuar razoavelmente a afirmar o princípio em todos os outros contextos, exceto o do paradoxo." (p. 10) Assim, restringe-se a validade dos princípios lógicos, excluindo as proposições problemáticas de seu campo de atuação, de forma a deixar a racionalidade intocada. A meu ver, Ryan tem razão ao sustentar que, para Bayle, os paradoxos não têm o poder de atingir os princípios lógicos. Teria ele razão, entretanto, ao defender os primeiros princípios da maneira como o faz, tratando-os como exceção e deixando-os de lado?

Parece-me que os textos de Bayle dizem coisa diferente. Primeiro, devese observar que Bayle não fala de paradoxos, mas de sofismas: o "sofisma" do mentiroso, o "sofisma" dos sorites etc. Longe de ver um paradoxo para o qual é impossível dar uma solução, Bayle entende que argumentos como o do mentiroso não passam de sofismas. Logo, é natural que não possam atingir nossa confiança nos princípios lógicos. Assim, os sofismas lógicos, em vez de questionar nossos princípios lógicos que estão na base do raciocínio e inferência, são denunciados como raciocínios inaceitáveis.

O que é problemático no sofisma lógico, para Bayle, não é o princípio, mas a própria proposição particular em questão, como "esta afirmação é falsa". É o que os escolásticos chamavam de proposições seipsa falsificantes ( Euclide », D). O sofisma lógico consiste num "silogismo em que, pela razão mesma que um homem diz a verdade, prova-se que ele não a diz" ("Philetas", E). Ora, o sofisma lógico não teria por finalidade a rejeição de nossos princípios, mas diria respeito tão somente a uma proposição particular. Dessa forma, um sofisma lógico não teria o alcance que se poderia pretender, como o de destruir os princípios da racionalidade.

Bayle diz que "o [sofisma do] mentiroso não passa de uma sutileza pueril" ("Philétas", texto) e "que basta um pouco de bom senso para conhecer a ilusão desses tipos de sofismas" ("Philétas", E). Na explicação sobre o sofisma dos sorites, Bayle deixa claro como o bom senso resolve as dificuldades desses sofismas. 
Um homem do mundo ridicularizaria com razão semelhantes inferências (ergoteries). Ele apelaria ao senso comum e, com esse grau de luz, no uso da vida civil, basta-nos discernir sem precisão o pouco, o muito etc.” (“Crisipo”, O).

Não perguntaríamos ao ébrio quantas gotas de cachaça ele bebe diariamente, mas quantas garrafas. Para o dialético, entretanto, que só opera com as "regras da arte", essa solução não é possível e, portanto, ele seria derrotado por semelhantes sofismas. Assim, a solução de Bayle não é uma solução lógico-filosófica, pois não recorre ao tribunal da razão, mas sim ao tribunal da vida civil e do senso comum ("Crisipo", O). Bayle não parece dar muito valor às tecnicalidades da lógica. Ao contrário, essas disputas sobre os sofismas lógicos têm dois defeitos graves. De um lado, não servem para corrigir o vício e, de outro, não conduzem ao conhecimento da verdade ("Euclide", E).

Em suma, Bayle não oferece uma resposta lógica aos sofismas lógicos, porque, dadas somente as regras da lógica, esses sofismas não têm solução. Não há nenhuma sugestão, por parte de Bayle, de excluir as proposições que contradiriam os princípios para salvar estes, porque o problema diz respeito às proposições particulares, não aos princípios. E, com relação a essas proposições particulares problemáticas, a vida comum se encarregaria de afastar as sutilezas lógicas dos dialéticos, ninguém se deixando enganar com argumentos sofísticos como esses. Os princípios da racionalidade permanecem, diante desses sofismas lógicos, inabalados.

A principal oposição que a razão encontra provém do método pirrônico da antinomia, que consiste em argumentar dos dois lados de uma questão. Por ser um método mais geral, pode incluir essas formas de argumentação. Por exemplo, Sexto Empírico e Carnéades teriam desenvolvido o argumento dos sorites, um sofisma lógico ("Crisipo", O). Embora não o tenham inventado, os céticos, desde Pirro, levaram esse método ao seu extremo, aplicando-o com um rigor e extensão inigualáveis ("Pirro", texto). Ao assim procederem, os céticos mostrariam que a razão está sistematicamente dividida em todas as questões, sem jamais conseguir estabelecer a vitória de uma das partes.

Um exemplo dessa antinomia é a disputa entre a via da autoridade e a via da consciência, pois o debate entre ambos os lados, apelando à retorsão, leva a uma disputa infindável, em que não há vencedores, apenas derrotados. Outro exemplo é a disputa sobre a origem do mal. Jamais decidiremos se o bem e o mal provêm de um único princípio ou de dois, como supõem os maniqueístas. Não se poderia decidir o conflito entre raciocínios a priori e raciocínios $a$ posteriori, nenhuma das partes impondo-se à outra ("Maniqueístas" D). Também no caso do vácuo, o que se observa, quando se trata de estabelecer 
uma verdade metafísica sobre a natureza das coisas, é uma espécie de empate entre os defensores do pleno, apoiados na ideia clara e distinta, e os defensores do vácuo, apoiados na experiência. $\mathrm{E}$, no caso da extensão, todas as teorias possíveis enredam-se em dificuldades inextricáveis, de tal forma que nenhuma triunfa e todas se destroem mutuamente ("Zenão", G).

Essas disputas somente poderiam ser decididas, no entender de Bayle, pela adoção arbitrária de um dos lados em questão. O dogmático revelaria, assim, sua parcialidade, já que se erigiria em juiz de uma disputa em que não passa de um dos litigantes. "Um homem que é juiz e parte não está em condições de discernir a verdade e a falsidade." ("Pellison", E) Uma visão mais neutra perceberia que nenhuma alternativa é satisfatória e suspenderia 0 juízo. "Nas disputas de religião, cada um é juiz e parte, pois as razões de seu adversário somente são examinadas depois de se revestir de um espírito cético e pirrônico" ("Pellison", E). Logo a seguir, Bayle, referindo-se à dificuldade de discernir verdade e falsidade, diz "que os juízes mais desinteressados e os próprios pirrônicos mais hábeis não saberiam para que lado se voltar." ("Pellison", E)

Essa contradição interna da razão, essa estrutura antinômica da razão, levaria à rejeição dos princípios básicos? Bayle diz que os pirrônicos combateram tudo, inclusive "as máximas da moral, as regras da lógica, os axiomas da metafísica" (III Esclarecimento, II). Carnéades teria chegado a usar toda sua sutileza argumentativa para mostrar que o princípio fundamental do silogismo (se duas coisas são iguais a uma terceira, então são iguais entre si), o mais evidente de todos, não seria evidente ("Carnéades" C). Qual, entretanto, a opinião de Bayle a esse respeito?

$\mathrm{O}$ veredicto de Bayle é explícito: os pirrônicos se perdem em seu próprio labirinto e nas suas próprias sutilezas (III Esclarecimento, II). Curiosamente, Bayle não expõe os argumentos que teriam levado Carnéades ao questionamento do princípio básico do silogismo e, mesmo sem analisálos, caracteriza-os como "sofismas". No entanto, nada na exposição de Bayle sugere que Carnéades negaria o princípio básico de todo raciocínio por causa do método de argumentar dos dois lados de uma questão. Quando Bayle expõe os famosos discursos de Carnéades em Roma, nenhuma relação entre o método cético da antinomia e o questionamento do princípio do silogismo é indicada. Bayle somente associa o ataque à evidência e clareza desse princípio à "sutileza" de Carnéades.

A aplicação do método antinômico por Bayle revela características peculiares. A primeira é a ideia de uma discussão interminável, em que a razão seria capaz de sustentar opiniões opostas ad infinitum. Haveria, de um 
lado, uma inegável força da razão, já que, com seus princípios inabaláveis e inabalados pela filosofia, teria recursos infinitos para sustentar uma tese contra as objeções. Mas, de outro lado, haveria uma evidente fraqueza da razão, porque esta jamais consegue estabelecer uma verdade e eliminar o adversário, de forma que as objeções sempre renascem. A constatação de que certas noções comuns devem ser aceitas não implica a descoberta ou estabelecimento de nenhuma verdade, nem põe a razão de acordo consigo mesma. Admitir os princípios básicos do raciocínio parece garantir uma discórdia eterna, não a paz entre as seitas filosóficas. Em vez de conduzir a uma paralisia da razão, o método antinômico promove uma produção interminável de discursos conflitantes.

Uma segunda peculiaridade é que a razão exibe um potencial destrutivo muito mais forte do que construtivo. São famosas as passagens de Bayle que sugerem que a razão seria incapaz de estabelecer qualquer verdade. "A razão humana é muito frágil para isso. É um princípio de destruição, não de edificação" ("Maniqueístas" D). ${ }^{4}$ Quando parece capaz de estabelecer uma tese, em geral será somente pela rejeição das alternativas. Um exemplo típico dessa argumentação é a extensão. As únicas teorias para explicar a realidade da extensão são: a extensão é infinitamente divisível; a divisão termina num ponto matemático sem dimensão; ou num ponto com dimensão física. Os dogmáticos raciocinam empregando um silogismo disjuntivo: (P1) ou T1 ou T2 ou T3; (P2) ora, nem T1, nem T2; (C1) portanto, T3. Assim, somente destruindo as alternativas a razão seria capaz de aderir a uma teoria. A teoria aceita, entretanto, seria excluída de um exame crítico, sendo os ataques adversários desconsiderados por algum motivo não-racional. ${ }^{5}$

O cético propõe uma generalização do procedimento crítico já empregado pelo dogmático, submetendo-lhe todas as teorias. Nenhuma objeção formulada por um adversário deve ser desconsiderada. Por isso, o cético reformula o tipo de argumento, não um silogismo disjuntivo, mas um silogismo hipotético: (P3) se A (a extensão é real), então B (ou T1 ou T2 ou T3); (P4) ora, não-B (nem T1, nem T2, nem T3); (C2) portanto não-A (a extensão não é real).

Note-se que o ceticismo (tal como desenvolvido por Bayle) é testemunho de um duplo compromisso com a razão. Primeiro, a posição cética é fruto de um argumento formalmente válido, deixando patente a aceitação dos princípios que regem os silogismos. Sua crítica ao dogmatismo não se dirige ao emprego de um silogismo, mas somente à parcialidade de seu exame racional, que se 
limita a criticar as outras doutrinas. Isso nos leva à segunda observação. A generalização desse procedimento destrutivo tornaria o ceticismo uma postura ainda mais racional que o dogmatismo, já que somente motivos não-racionais conduziriam os dogmáticos a rechaçar os ataques dos demais dogmáticos. Noutras palavras, P4 revela-se uma premissa mais razoável do que P2. Esse compromisso, no entanto, é paradoxal, já que as objeções são sempre mais fortes que as defesas ${ }^{6}$ e, se o debate é interminável, não é porque os dois lados têm recursos suficientes para defender-se, mas porque têm recursos para prosseguir atacando. ${ }^{7}$ Ao aderir à razão, o cético mostraria que esta não conduz à verdade.

\section{Conclusão}

Vimos que o argumento ad hominem era insuficiente para questionar as ideias claras e os princípios básicos, limitando-se a corrigir consequências equivocadamente extraídas de ideias ou princípios particulares. Esse tipo de argumento é antes uma exigência de coerência com os princípios assumidos por um filósofo, do que uma condenação da razão humana. Ainda assim, muitas filosofias são condenadas por não inferirem corretamente o que se segue de seus princípios. A retorsão, embora parecesse uma eficiente defesa contra algumas objeções, revelou-se uma forma de condenar as duas teorias envolvidas, já que ambas sucumbiriam às mesmas objeções. Assim, esse seria um segundo teste de coerência: uma teoria satisfatória deve ser capaz de responder às objeções formuladas contra as outras teorias. Portanto, a razão é inteiramente preservada pela retorsão, mas não algumas filosofias. A experiência, por sua vez, revelou ter força suficiente para questionar verdades estabelecidas somente por razões a priori. Assim, quando se extrai de uma ideia clara uma consequência que é contradita pela experiência, Bayle afirma que essa ideia "nos enganou miseravelmente". Os princípios, no entanto, pareciam fora do alcance dos argumentos a posteriori. Uma teoria deve ser coerente com o que se observa na experiência.

Poderiam os princípios fundamentais, nos quais se alicerça nossa razão, serem questionados? A razão humana permanece de pé mesmo diante de argumentos supostamente mais poderosos que os anteriores. A tremenda

6 Cf. "Arriaga”, B; "Zenão”, G; "Rorarius”, G.

7 Solère (2003, p. 99) diz que, em Bayle, "as teses se alimentam da refutação de suas opostas e, por sua vez, são vítimas dessas antíteses; a razão tem estrutura antinômica e se esgota numa luta intestina, numa dialética infinita, que rapidamente assume um feitio erístico, o ataque sendo sempre mais forte que a defesa, o a favor e o contra podendo ser igualmente bem sustentados." 
força que o cristianismo emprestaria ao ceticismo, aparentemente destruindo todos os princípios (morais, metafísicos e lógicos), somente é possível a partir da adoção de certos dogmas religiosos não questionados. Mas a razão, ao tudo examinar e ao proceder claramente, não parte e não pode partir desses pressupostos arbitrários, sujeitos à controvérsia e, sobretudo, misteriosos ou ininteligíveis. As ideias claras permanecem a baliza de todo raciocínio filosófico e, assim, todos os princípios são preservados ao abrigo da dúvida ocasionada pelos dogmas cristãos. Mesmo os paradoxos lógicos não seriam capazes de pôr em xeque os princípios da razão. Para Bayle, não passam de sofismas, facilmente refutáveis na vida cotidiana; no melhor dos casos, apenas problematizam proposições específicas, mas não os princípios lógicos. Finalmente, Bayle aparentemente não estabeleceu nenhum vínculo entre o método cético da antinomia e a abolição dos princípios lógicos. Se os céticos os negaram, foi por razões que Bayle, infelizmente, não expôs. Ao contrário, seu uso desse método mostra um compromisso com os princípios lógicos, já que os argumentos céticos empregam formas lógicas válidas, como o silogismo hipotético. No entanto, sua aplicação generalizada às teorias filosóficas, aniquilando-as todas, mostrou não ser possível alcançar a verdade.

É hora de concluir. De um lado, nenhum tipo de argumento é capaz de anular o bom funcionamento da razão, nem mesmo o conjunto desses argumentos seria capaz disso. Não somente os princípios permanecem inabalados, mas também as ideias claras continuam a ser uma referência indispensável para o nosso pensamento. De outro lado, entretanto, alguns tipos de argumento contribuem para eliminar as teorias filosóficas que pretendem desvendar a verdade. Um teste indispensável para estas é a coerência, seja com os seus princípios, com objeções formuladas a outras teorias ou com a experiência. Muitas vão ficando pelo caminho ao se submeterem a esse teste. $O$ grande obstáculo para estabelecer a verdade, mesmo quando a razão funciona adequadamente, é o método cético da antinomia. Este revela como a razão, cindida em diversas teorias conflitantes, é incapaz de optar por uma delas como a verdadeira, obtendo êxito somente na ofensiva, jamais na defensiva. ${ }^{8}$ Desta forma, a razão deve contentar-se, não com a verdade de teses sobre as coisas em si mesmas, mas com a probabilidade de certas hipóteses. ${ }^{9}$

8 Por isso, a estratégia constante de Bayle, segundo Solère (2004, p. 170), seria "aniquilar os sistemas uns pelos outros, mostrando que eles se destroem mutuamente com dificuldades irrefutáveis e que a razão conduz de um lado e do outro a impasses, revelando-se incapaz de decidir a favor ou contra cada uma das duas hipóteses."

9 Em outro artigo, espero voltar a esse assunto. 


\section{Bibliografia}

BAYLE, P. Dictionnaire historique et critique, USA: Elibron Classics, 2005, facsimile da edição de Paris : Dsoer, 1820.

MORI, G., (2003b) « Pierre Bayle on scepticism and common notions » in Paganini, G. (ed.) The Return of Scepticism: From Hobbes and Descartes to Bayle, Dordrecht/ Boston/London: Kluwer Academic Publishers, p. 393-413.

ROBERT, P. La raison corrosive. Études sur la pensée critique de Pierre Bayle, Paris : Honoré Champion, 2003.

RYAN, T. «Évolution et cohérence du fidéisme baylien : le paradoxe du 'fidéisme raisonnable' ", no prelo.

SOLÈRE, J.-L. (2003) "Bayle et les apories de la raison humaine" in Delpla, I. e de SOLÈRE, J.-L. (2004) "Bayle et les théologiens" in McKenna, A. et Paganini, G. (org.) Pierre Bayle dans la République des Lettres: Philosophie, religion critique, Paris : Honoré Champion, p. 129-170. 